\title{
Clinicopathologic features and therapy outcome in childhood Hodgkin's lymphoma: a report from tertiary care center in Saudi Arabia
}

\author{
Nawaf Alkhayat ${ }^{1}$, Mohammad Alshahrani ${ }^{1 *}$ (D), Ghaleb Elyamany², Qanita Sedick², Walid Ibrahim', \\ Hasna Hamzi ${ }^{1}$, Amal Binhassan ${ }^{1}$, Mohamed Othman', Saeed Alshieban³, Mansour S. Aljabry ${ }^{4}$, Shuaa Asiri², \\ Muneerah Alzouman², Omar Alsuhaibani ${ }^{2}$, Fahad Alabbas' ${ }^{1}$, Omar Alsharif ${ }^{1}$ and Yasser Elborai ${ }^{5}$
}

\begin{abstract}
Background: Hodgkin lymphoma ( $\mathrm{HL}$ ) is lymphoid neoplasm usually affecting lymphatic system; it accounts $3.6 \%$ of cancers in Saudi Arabia. Modern treatment protocols had shown particular success rates in overall-survival (OS) and event-free-survival (EFS). In our study, we reviewed the medical records of 80 pediatric and young adolescent patients diagnosed HL from January 2006 to July 2020, treated at tertiary care hospital in Riyadh, Saudi Arabia. Demographic, clinical, and pathological data were explored. First line therapy was ABVD, COG, COPP, R-CHOP, or radiotherapy alone in 53/80 (66.4\%), 24/80 (30\%), 1/80 (1.2\%), 1/80 (1.2\%), or 1/80 (1.2\%) patients; respectively. Response assessment was done by $C T+/$ - PET scan after first 2 cycles then every 2 cycle and end of therapy. Another assessment was done if any clinical suspicion of recurrence.
\end{abstract}

Results: Median age 11 (range 3-16) years. Males to females 1.3:1. Seventy-two out of eighty (90\%) patients showed first complete remission (CR1) and maintained remission for median 40 (range 7-136) months. Eight out of eighty (10\%) patients showed refractory disease. Nineteen patients received salvage therapy (ICE or ESHAP/brentuximab vedotin or gemcitabine/brentuximab vedotin), 14/19 (73.7\%) had 2nd complete remission (CR2) for median time 24 (ranged 9-78) months, while 5/19 (26.3\%) did not show any response. Five-year OS and EFS were 95\% and 75\%. Two patients had 2ry malignant neoplasms, one had AML and died, the other had malignant fibrous histocytoma and still alive. None of our patients had fertility problem. Also, they did not experience chronic pulmonary or cardiotoxicity. Classic Hodgkin's lymphoma: nodular sclerosis subtype was more prominent (55\%) than mixed cellularity subtype (22.5\%), which is similar to several European and US studies, lymphocyte rich (11.25\%) and lymphocyte depleted (0\%), while nodular lymphocyte predominant Hodgkin's lymphoma (11.25\%).

Conclusions: Our study provided unique descriptive study of childhood HL, in Saudi Arabia, with valuable insight into the long-term outcome and late toxicity. Our results are comparable to other studies in the Middle East and European countries.

Keywords: Pediatric Hodgkin lymphoma, Long-term outcome, Late toxicity, Saudi Arabia

\footnotetext{
*Correspondence: drshahranim@yahoo.com

1 Department of Pediatric Hematology/Oncology, Prince Sultan Military Medical City, Riyadh, Riyadh 11159, Saudi Arabia

Full list of author information is available at the end of the article
}

\begin{abstract}
Background
Hodgkin lymphoma (HL) is lymphoid neoplasm usually affecting lymph nodes and the lymphatic system; it is considered to be among the hematological malignancies with the best prognosis [1]. In childhood and young adolescence, HL has shown to display heterogeneous clinical
\end{abstract}


and pathological manifestations and appears to vary according to the epidemiological and geographic origin of the disease [2]. Some studies have also found HL manifestations to be correlated to socio economic levels and immunologic status $[3,4]$.

HL accounts for $30 \%$ of all lymphomas and $5-6 \%$ of all childhood cancers [5]. In the USA, it accounts for approximately $7 \%$ of childhood cancers and $1 \%$ of childhood deaths. And in developed countries, HL accounts for approximately $10 \%$ of all lymphomas and $0.6 \%$ of all cancer diagnoses [6], while HL accounts for $3.6 \%$ of all cancers in Saudi Arabia [7].

Data shows that the number of Hodgkin lymphoma (HL) in the Middle East has increased over the past decade especially in younger age groups [8], in parallel to reduced HL associated mortalities worldwide between 2005 and 2015 [9]. Improvement in living conditions, healthcare systems, and modern treatment protocols have contributed to improved mortality [10]. Indeed, the modern treatment protocols for HL has shown particular success rates in children with the 5-year event-free survival (EFS) in childhood and adolescence exceeding 90\% for early onset disease and $80 \%$ for late onset advanced stage disease [11].

To the best of our knowledge, there is a paucity of data available which describes the clinic-pathological features and survival rate of childhood and adolescent $\mathrm{HL}$ in the Middle East and Saudi Arabia. The recent increased prevalence of HL occurring in children and young adults [8] prompted us to review the clinic-pathological data and survival outcome of HL in Saudi Arabia.

\section{Methods}

\section{Study population}

The data were reviewed, retrospectively, through the medical records of 89 pediatric and young adolescent patients diagnosed as HL between the period January 2006 and July 2020 treated in our tertiary institution in Riyadh, Saudi Arabia. The study was approved by the research and ethics committee with the institute review board (IRB) number 1390 (HP-01-R079).

The patients' records were searched for all demographic, clinical, radiological, laboratory, treatment protocol, and follow up data. The diagnosis of HL was confirmed histologically by examination of a lymph node biopsy/tissue and confirmed with immunohistochemical stains according to the World Health Organization (WHO) classification [12]. All patients were assessed physically and radiologically. They all had contrastenhanced computed tomography (CT) scan of the neck, chest, abdomen, and pelvis initially for staging. Positron emission tomography (PET) scan was performed initially for most of the patients; few patients missed it because of technical issues. Response assessment by CT $+/-$ PET scan was performed after first 2 cycles then every 2 cycles and end of therapy. If PET scan was not available, we built up the response criteria upon the results of $\mathrm{CT}$ according to the protocol. Bone marrow aspiration and trephine biopsies were performed on the selected patients to diagnose bone marrow metastasis if clinically indicated, stage III/IV or low parameters of complete blood count (CBC) which may indicate bone marrow involvement.

Our patients were staged according to the Cotswold modification of the Ann Arbor staging [13]. Risk assessment was performed at diagnosis: stages IA and IIA without bulky disease or extra nodal extension were considered as low-risk; stage IA or IIA with bulky disease or extra nodal extension, stage IB or IIB, and stage IIIA were considered as intermediate risk, while stages IIIB and IV were considered as high risk [14]. Bulky disease was defined as a single node $>6 \mathrm{~cm}$ or a multiple amalgamated nodes tumor mass of $>10 \mathrm{~cm}$. Early stage considered as stages I and II, while advanced stage considered as stages III and IV. Response assessment and follow-up were based on the Cheson criteria [15].

\section{Treatment protocols and follow-up policy}

Different protocols were used as 1st line of treatment. Fifty-three patients received doxorubicin (adriamycin), bleomycin, vinblastine, and dacarbazine (ABVD) in the period between the beginning of the study in 2006 till end of 2015, 2 cycles of ABVD for low risk, 4 cycles for intermediate risk, and 6 cycles for high risk. Twenty-four patients received Children's Oncology Group (COG) protocols (low risk AHOD0431, intermediate risk AHOD0031, and high risk AHOD0831) in the period between 2016 till end of study in July 2020 . One patient, high risk stage IIIB, received cyclophosphamide, vincristine, procarbazine, prednisone (COPP) due to severe heart failure. Another patient, intermediate risk stage IIIA, received rituximab-cyclophosphamide, hydroxydaunomycin, vincristine, and prednisolone (R-CHOP), Although this chemotherapy was not the standard of care, but the decision was taken by primary physician based on pathology subtype, nodular lymphocyte predominant Hodgkin's lymphoma. Only one patient received radiotherapy alone as 1st line therapy, because his risk stratification was low risk stage IA, the primary physician took this decision although it is not the standard of care. Unfortunately, he relapsed and went in remission after salvage therapy.

Involved filed radiotherapy (IFRT) was given to $41 / 80$ (53.3\%) patients after completion of different chemotherapy protocols (ABVD \& COG) according to the risk assessment, bulky disease, and response to treatment. For low risk patients, IFRT was given to all patients who 
did not have a complete response (CR) after receiving 3 cycles of chemotherapy. For intermediate risk patients, IFRT was given to; slow early responders (SER) who had less than very good partial response $(<\mathrm{VGPR},<60 \%$ reduction of initial volume) following 2 cycles of chemotherapy. Also, IFRT was given to rapid early responders (RER) who had CR or VGPR following 2 cycles of chemotherapy but failed to get CR after 4 cycles of chemotherapy, while IFRT was omitted to RER following 2 cycles of chemotherapy and successfully got CR after 4 cycles of chemotherapy. For high risk patient, IFRT was riskadapted with an intended volume reduction to reduce toxicity. RER who had CR after first 2 cycles of chemotherapy, only got IFRT to the initial bulk disease. While SER who had partial response (50\% of initial volume) or stable disease ( $>50 \%$ of initial volume), sites that remain PET avid after the initial 2 cycles chemotherapy will be irradiated as well as any site (regardless of avidity) that remains $\geq 2.5 \mathrm{~cm}$ at completion of all chemotherapy. The dose of IFRT was 21 Gy in 14 fractions of 1.5 Gy per day. Treatment began within 3-4 weeks after completion of the last cycle of chemotherapy provided that recovered blood counts. Response criteria depended on results of PET scan. In 9/80 patients who did not have PET scan due to technical issues, minimal two perpendicular dimensions in $\mathrm{CT}$ scan were used to determine the response criteria.

Second line of chemotherapy was given to the patients who had refractory or relapsed disease. Refractory disease was defined as stable disease after completion of treatment protocol (50\% of the initial volume of LNDs) with viable cell confirmed by histopathology, or progressive disease at any time during treating protocol, confirmed by histopathology. While relapsed disease was defined as recurrence of disease after variable periods of complete remission post first line therapy, the second line therapy includes different protocols of chemotherapy: ICE (ifosfamide, carboplatin, etoposide) or ESHAP (etoposide, solu-medrol, high dose ara-c, platinum "cisplatin")/brentuximab vedotin, or gemcitabine/brentuximab vedotin. If the patient got in remission by second line chemotherapy, this remission was consolidated by high dose chemotherapy and autologous stem cell rescue.

Patients underwent follow-up with clinical examinations, chest X-ray, and abdominal ultrasound at 3-month intervals for the first 3 years, then at 6-month intervals till 5 years, and then yearly. More investigations on follow-up were performed only if indicated.

\section{Statistical analysis}

The data was statistically described using number (percent). Association between variables and groups is performed using chi-square test or Fisher exact test.
Overall and event-free survival curves are calculated using Kaplan-Meier test. Statistical package for social sciences (SPSS) computer program (version 19 windows) was used for data analysis. $P$ value $\leq 0.05$ was considered significant.

\section{Results}

We collected data from 89 pediatric patients diagnosed as HL, 9 cases were excluded due to incomplete data or lost follow up, 80 patients were admitted in our tertiary care institution in Riyadh Saudi Arabia with confirmed HL during the period between January 2006 and July 2020 . The median age was 11 years old with range 3-16 years. The cohort study included 45 males and 35 females with 1.3:1 male to female ratio. Laboratory data and other clinical data; B symptoms (fever, weight loss, and night sweats), primary site, bulky disease, extra nodal involvement, presence of Epstein-Barr virus, pathology subtypes, stages, and risk groups, were presented in Table 1.

\section{Response to therapy}

All patients received 1st line of treatment which was chemotherapy alone, radiotherapy alone, or combination of both chemotherapy/radiotherapy; 38/80 (47.5\%), $1 / 80(1.2 \%)$, or $41 / 80(51.3 \%)$, respectively. The first line chemotherapy was ABVD, COG, COPP, or R-CHOP in $53 / 80$ (66.4\%), $24 / 80(30 \%), 1 / 80(1.2 \%)$, or $1 / 80(1.2 \%)$ patients, respectively. Most of the patients 72/80 (90\%) showed complete remission after first line therapy (CR1) and maintained remission for median 40 months and range $7-136$ months, while $8 / 80(10 \%)$ patients did not show any response, refractory disease.

Nineteen patients received second line (salvage) therapy, eight patients were refractory and eleven patients relapsed after median period of maintaining remission 30 months ranged 3-96 months. The salvage therapy was either chemotherapy alone $7 / 19(36.8 \%)$ or chemotherapy followed by stem cell rescue 12/19 (63.2\%). Response to salvage therapy showed 14/19 (73.7\%) patients had 2nd complete remission (CR2) for median time 24 months ranged (9-78) months, while $5 / 19(26.3 \%)$ patients did not show any response (Table 2).

Table 3 presents a number of clinical factors and their correlation with CR1. Statistical analysis of these factors revealed that B symptoms, stage, and risk groups have significant correlation with remission rate after 1st line therapy, $P=0.05, P=0.022, P=0.012$, respectively. While other factors, age, gender, primary site, bulky disease, extra nodal involvement, and pathology subtypes, did not show any clinical significant with rate of CR1.

Table 4 presents group of patients 19/80, who are refractory to 1st line therapy or relapsed after CR1. 
Table 1 Clinical and demographic data

\begin{tabular}{|c|c|c|}
\hline & No & $\%$ \\
\hline \multicolumn{3}{|l|}{ Age (years) } \\
\hline$<5$ & 3 & 3.7 \\
\hline $5-9.99$ & 23 & 28.8 \\
\hline$\geq 10-16$ & 54 & 67.5 \\
\hline \multicolumn{3}{|l|}{ Gender } \\
\hline Male & 45 & 56.3 \\
\hline Female & 35 & 43.7 \\
\hline \multicolumn{3}{|l|}{ B symptoms } \\
\hline No & 46 & 57.5 \\
\hline Yes & 34 & 42.5 \\
\hline \multicolumn{3}{|l|}{ Primary site } \\
\hline Peripheral lymph nodes & 65 & 81.25 \\
\hline Mediastinum & 15 & 18.75 \\
\hline \multicolumn{3}{|l|}{ Bulky } \\
\hline No & 59 & 73.8 \\
\hline Yes & 21 & 26.2 \\
\hline \multicolumn{3}{|l|}{ Extra nodal involvement } \\
\hline No & 51 & 63.8 \\
\hline Yes & 29 & 36.2 \\
\hline \multicolumn{3}{|l|}{ Epstein-Barr virus } \\
\hline Positive & 40 & 50 \\
\hline Negative & 5 & 6.3 \\
\hline N/A & 35 & 43.7 \\
\hline \multicolumn{3}{|l|}{ Pathology } \\
\hline \multicolumn{3}{|l|}{ Classic Hodgkin's lymphoma } \\
\hline Lymphocyte rich & 9 & 11.25 \\
\hline Mixed cellularity & 18 & 22.5 \\
\hline Nodular sclerosis & 44 & 55 \\
\hline Lymphocyte depleted & 0 & 0 \\
\hline $\begin{array}{l}\text { Nodular lymphocyte predominant Hodg- } \\
\text { kin's lymphoma }\end{array}$ & 9 & 11.25 \\
\hline \multicolumn{3}{|l|}{ Stage } \\
\hline 1 & 5 & 6.3 \\
\hline$\|$ & 25 & 31.2 \\
\hline III & 42 & 52.5 \\
\hline IV & 8 & 10 \\
\hline \multicolumn{3}{|l|}{ Early and advanced stages } \\
\hline Early $(I, I)$ & 30 & 37.5 \\
\hline Advanced (III, IV) & 50 & 62.5 \\
\hline \multicolumn{3}{|l|}{ Risk group } \\
\hline Low & 12 & 15 \\
\hline Intermediate & 44 & 55 \\
\hline High & 24 & 30 \\
\hline \multicolumn{3}{|l|}{ Laboratory data: median (range) } \\
\hline WBC $\left(\times 10^{9} / \mathrm{l}\right)$ & $7.4(2.3-31.6)$ & \\
\hline $\mathrm{HGB}\left(\times 10^{9} / \mathrm{l}\right)$ & $11.8(6.1-15.2)$ & \\
\hline $\operatorname{PLT}\left(\times 10^{9} /\right)$ & $357(27-856)$ & \\
\hline $\operatorname{LDH}(\mu / l)$ & $266.5(131-1164)$ & \\
\hline
\end{tabular}

WBC white blood cells, $H G B$ hemoglobin, $P L T$ platelet, $L D H$ lactate dehydrogenase
Univariate analysis of initial presentation shows factors that have significant correlation with this relapsed/ refractory $(\mathrm{R} / \mathrm{R})$ group. B symptoms and risk groups have a significant correlation with relapsed/refractory group, $P=0.037$ and 0.009 , respectively. Other clinical factors did not show any significant correlation with relapsed/refractory (R/R) group.

\section{Long-term outcome and late toxicity}

A total of 76/80 (95\%) patients were alive. Seventy patients were alive in complete remission without any late toxicity. Two patients were alive with disease. One patient developed chemotherapy related toxicity which is moderate loss of hearing acuity after 4 cycles of ICE salvage therapy. Three patients developed complications within the field of radiotherapy; one patient had secondary neoplasm of malignant fibrous histocytoma at neck of left femur which was the metastatic site of initial disease and received local radiotherapy on it; two patients received IFRT on neck, one developed nasopharyngeal mass showed reactive lymphoid hyperplasia, and the other one developed hypothyroidism. None of our patients complained of any fertility problem. Also, they did not experience chronic pulmonary or cardiac toxicity.

Four patients died 4/80 (5\%), 3 patients died of disease progression and one died of 2ry neoplasm. The three patients who died of disease progression; 2 of them were high risk HL (stage III B non-bulky) refractory to the first line therapy and did not respond to the second line therapy and died of disease, the third patient also was high risk HL (stage III B non-bulky), he responded to the first line therapy ABVD and maintained remission for 96 months but he relapsed and did not respond to 2nd line therapy and died of disease. The patient who died of 2ry neoplasm, he was diagnosed as intermediate risk HL (stage IIIA, non-bulky), he received ABVD with IFRT, he was in remission for 54 months but developed 2ry acute myeloid leukemia (AML) and died of 2ry neoplasm.

The overall 5-year survival (OS) rates and event-free survival (EFS) rate of our study were $95 \%$ and $75 \%$, respectively (Fig. $1 \mathrm{~A}$ and $\mathrm{B}$ ). Univariate analysis of early (I and II) and advanced (III and IV) stages showed that, OS was $100 \%$ and $92 \%$ without statistical significance $(p=0.24)$, while EFS was $87 \%$ and $68 \%$, respectively, with borderline significance $p=0.046$ (Fig. 2 $\mathrm{A}$ and $\mathrm{B}$ ). Also, univariate analysis of risk factor (low, intermediate, and high) showed OS 100\%, 97\%, and $87 \%$, respectively $(p=0.68)$, while EFS $91 \%, 81 \%$, and $54 \%$, respectively, with significant $p=0.028$ (Fig. 3 A and $\mathrm{B})$. 
Table 2 Salvage treatment and outcome of all refractory/relapsed patients

\begin{tabular}{|c|c|c|c|c|}
\hline \# of patient & Second line of chemotherapy & HSCT & Response & Outcome \\
\hline \multicolumn{5}{|c|}{ Refractory patients } \\
\hline 1 & ICE & Yes & $\mathrm{RD}$ & Died from disease \\
\hline 2 & ESHAP/brentuximab vedotin & Yes & CR2 & Alive in CR \\
\hline 3 & ICE & Yes & CR2 & Alive in CR \\
\hline 4 & ESHAP/brentuximab vedotin & Yes & CR2 & Alive in CR \\
\hline 5 & ICE & No & $\mathrm{RD}$ & Died from disease \\
\hline 6 & ICE then ESHAP/brentuximab vedotin & No & $\mathrm{RD}$ & Alive with disease \\
\hline 7 & ICE & Yes & CR2 & Alive in CR \\
\hline 8 & ICE then ESHAP/brentuximab vedotin & Yes & CR2 & Alive in CR \\
\hline \multicolumn{5}{|c|}{ Relapsed patients } \\
\hline 1 & ICE then gemcitabine/brentuximab vedotin & No & $\mathrm{RD}$ & Died from disease \\
\hline 2 & ICE & No & CR2 & Alive in $C R$ \\
\hline 3 & ICE & No & CR2 & Alive in $C R$ \\
\hline 4 & ICE & No & CR2 & Alive in $C R$ \\
\hline 5 & ICE & Yes & CR2 & Alive in CR \\
\hline 6 & ICE & Yes & CR2 & Alive in CR \\
\hline 7 & ESHAP/brentuximab vedotin & Yes & CR2 & Alive in CR \\
\hline 8 & ICE & Yes & CR2 & Alive in CR \\
\hline 9 & Refused treatment & No & $\mathrm{RD}$ & Alive with disease \\
\hline 10 & ICE then gemcitabine/brentuximab vedotin & Yes & CR2 & Alive in $C R$ \\
\hline 11 & ESHAP/brentuximab vedotin & Yes & CR2 & Alive with 2ry neoplasm \\
\hline
\end{tabular}

ICE ifosfamide/carboplatin/etoposide, ESHAP etoposide/solu-medrol/high dose ara-c/platinum-cisplatin, HSCT hematopoietic stem cell transplant, CR2 second complete remission, $C R$ complete remission, $R D$ refractory disease

\section{Discussion}

HL is considered a highly curable disease among other malignancies; it has a worldwide clinical and epidemiological variation [16]. Our study discussed the epidemiological, clinical characteristics, and current management strategies with special attention to longterm outcome and late toxicity of pediatric HL in one of the biggest referral center in Saudi Arabia.

Our cohort revealed male: female ratio 1.3:1; this male predominance and other clinical feature like older age at presentation were reported in many other studies $[17,18]$. Nodal presentation, in our cohort, is more prominent than extra-nodal presentation, $63.8 \%$ and $36.2 \%$ respectively, which are the same clinical features reported by Sherief et al. [17].

In our cohort, advanced or extensive disease (stages III-IV) showed a higher percentage than early or localized one (stages I-II); they were $62.5 \%$ and $37.5 \%$ respectively. Other countries with low socioeconomic level showed a similar percentage [19], Sherief et al. showed a higher percentage of advanced stage $56 \%$ in comparison to the early stage $44 \%$ [17]. In contrast, the European countries with higher socioeconomic level showed a lower percentage of advanced disease, may be due to early diagnosis, Aquino et al. showed early and advanced stages, $70 \%$ and $30 \%$, respectively [16].

According to WHO, HL classified into classic HL (cHL) represented $95 \%$ of all HL which incorporate 4 subtypes; nodular sclerosis (NS), mixed cellularity (MC), lymphocyte rich (LR) and lymphocyte depleted (LD), and nodular lymphocyte predominant Hodgkin's lymphoma (NLPHL) represented 5\% of all HL [20]. In our cohort, the percentage of cHL and NLPHL were $88.7 \%$ and $11.3 \%$; respectively. NS subtype was more prominent than MC, $55 \%$ and $22.5 \%$ respectively, which is similar to several European and US studies [16, 21]. On the other hand, some developing countries showed that MC subtype was more prominent than NS. In Egypt, MC and NS were $50.8 \%$ and $28.9 \%$ respectively [17]; in Nicaragua MC and NS, subtypes were $52.1 \%$ and $31 \%$ respectively [19], and in India MC subtype was 71\% [22]. No cases detected with LD among our cohort.

The pathogenesis of HL in childhood has been largely attributed to viral oncogenic pathway stimulation. Epstein-Barr virus (EBV) has been identified, serologically by detecting IgG and IgM, as the most common associated virus. Genetic predisposition has also been associated in some cases [23]. The majority of patients 
Table 3 Factors affecting the response to 1st line therapy

\begin{tabular}{|c|c|c|c|}
\hline & CR1 $(n=72)$ & Non-CR1 $(n=8)$ & $P$ value \\
\hline \multicolumn{4}{|l|}{ Age (years) } \\
\hline$<5$ years $(n=3)$ & $3(4.2 \%)$ & $0(0.0 \%)$ & \multirow[t]{3}{*}{0.118} \\
\hline $5-9.99$ years $(n=23)$ & $23(31.9 \%)$ & $0(0.0 \%)$ & \\
\hline$\geq 10$ years $(n=54)$ & $46(63.9 \%)$ & $8(100.0 \%)$ & \\
\hline \multicolumn{4}{|l|}{ Gender } \\
\hline Female $(n=35)$ & $32(44.4 \%)$ & $3(37.5 \%)$ & \multirow[t]{2}{*}{0.707} \\
\hline Male $(n=45)$ & $40(55.6 \%)$ & $5(62.5 \%)$ & \\
\hline \multicolumn{4}{|l|}{ B symptoms } \\
\hline No $(n=46)$ & $44(61.1 \%)$ & $2(25.0 \%)$ & \multirow[t]{2}{*}{$0.050^{*}$} \\
\hline Yes $(n=34)$ & $28(38.9 \%)$ & $6(75.0 \%)$ & \\
\hline \multicolumn{4}{|l|}{ Primary site } \\
\hline $\begin{array}{l}\text { Peripheral lymph nodes } \\
\quad(n=65)\end{array}$ & $58(80.6 \%)$ & $7(87.5 \%)$ & \multirow[t]{2}{*}{0.286} \\
\hline Mediastinum $(n=15)$ & $14(19.4 \%)$ & $1(12.5 \%)$ & \\
\hline \multicolumn{4}{|l|}{ Bulky } \\
\hline No $(n=59)$ & $52(72.2 \%)$ & $7(87.5 \%)$ & \multirow[t]{2}{*}{0.351} \\
\hline Yes $(n=21)$ & $20(27.8 \%)$ & $1(12.5 \%)$ & \\
\hline \multicolumn{4}{|l|}{ Extra nodal involvement } \\
\hline No $(n=51)$ & $48(66.7 \%)$ & $3(37.5 \%)$ & \multirow[t]{2}{*}{0.104} \\
\hline Yes $(n=29)$ & $24(33.3 \%)$ & $5(62.5 \%)$ & \\
\hline \multicolumn{4}{|l|}{ Pathology } \\
\hline $\begin{array}{l}\mathrm{CHL}, \text { nodular sclerosis } \\
(n=44)\end{array}$ & $39(54.2 \%)$ & $5(62.5 \%)$ & \multirow[t]{4}{*}{0.395} \\
\hline $\begin{array}{l}\mathrm{CHL} \text {, mixed cellularity } \\
\quad(n=18)\end{array}$ & $15(20.8 \%)$ & $3(37.5 \%)$ & \\
\hline $\begin{array}{l}\mathrm{CHL} \text {, lymphocyte rich } \\
\quad(n=9)\end{array}$ & $9(12.5 \%)$ & $0(0.0 \%)$ & \\
\hline $\mathrm{NLPHL}(n=9)$ & $9(12.5 \%)$ & $0(0.0 \%)$ & \\
\hline \multicolumn{4}{|l|}{ Stage } \\
\hline Early $(\mathrm{I}, \mathrm{II})(n=30)$ & $30(41.7 \%)$ & $0(0.0 \%)$ & \multirow[t]{2}{*}{$0.022^{*}$} \\
\hline Advanced (III, IV) $(n=50)$ & $42(58.3 \%)$ & $8(100.0 \%)$ & \\
\hline \multicolumn{4}{|l|}{ Risk group } \\
\hline $\operatorname{Low}(n=12)$ & $12(16.7 \%)$ & $0(0.0 \%)$ & \multirow[t]{3}{*}{$0.012^{*}$} \\
\hline Intermediate $(n=44)$ & $42(58.3 \%)$ & $2(25.0 \%)$ & \\
\hline $\operatorname{High}(n=24)$ & $18(25.0 \%)$ & $6(75.0 \%)$ & \\
\hline
\end{tabular}

Data are expressed as number (\%); $p>0.05=$ not significant; $p \leq 0.05=$ significant. $C R 1$ complete remission after $1 \mathrm{st}$ line of therapy, Non-CR1 not in complete remission after 1st line of therapy, $\mathrm{CHL}$ classic Hodgkin's lymphoma, NLPHL nodular lymphocyte predominant Hodgkin lymphoma
Table 4 Factors affecting the relapse/refractory (R/R) rate

Not $\mathrm{R} / \mathrm{R}(n=61) \quad \mathrm{R} / \mathrm{R}(n=19) \quad P$ value

Age (years)

$\begin{array}{rll}<5 \text { years }(n=3) & 3(4.2 \%) & 0(0.0 \%) \\ 5-9.99 \text { years }(n=23) & 21(34.4 \%) & 2(10.5 \%) \\ \geq 10-16 \text { years }(n=54) & 37(60.7 \%) & 17(89.5 \%)\end{array}$

Gender

$\begin{array}{llll}\text { Female }(n=35) & 26(42.6 \%) & 9(47.4 \%) & 0.716 \\ \text { Male }(n=45) & 35(57.4 \%) & 10(52.6 \%) & \\ \text { B symptoms } & & & \end{array}$

$\begin{array}{llll}\text { No }(n=46) & 39(63.9 \%) & 7(36.8 \%) & 0.037^{*} \\ \text { Yes }(n=34) & 22(36.1 \%) & 12(63.2 \%) & \end{array}$

Primary site

Peripheral lymph nodes
$(n=65)$$\quad 51(83.6 \%) \quad 14(73.7 \%) \quad 0.422$

$\begin{array}{llll}\text { Mediastinum }(n=15) & 10(16.4 \%) & 5(26.3 \%) & \\ \text { Bulky } & & & \\ \text { No }(n=59) & 45(73.8 \%) & 14(73.7 \%) & 0.994 \\ \text { Yes }(n=21) & 16(26.2 \%) & 5(26.3 \%) & \end{array}$

Extra nodal involvement

$\begin{array}{llll}\text { No }(n=51) & 40(65.6 \%) & 11(57.9 \%) & 0.543 \\ \text { Yes }(n=29) & 21(34.4 \%) & 8(42.1 \%) & \end{array}$

Pathology

$\begin{array}{llll}\begin{array}{c}\mathrm{CHL}, \text { nodular sclerosis } \\ (n=44)\end{array} & 35(57.4 \%) & 9(47.4 \%) & 0.827 \\ \begin{array}{c}\mathrm{CHL}, \text { mixed cellularity } \\ (n=18)\end{array} & 13(21.3 \%) & 5(26.3 \%) & \\ \begin{array}{c}\mathrm{CHL}, \text { lymphocyte rich } \\ (n=9)\end{array} & 6(9.8 \%) & 3(15.8 \%) & \\ \mathrm{NLPHL}(n=9) & 7(11.5 \%) & 2(10.5 \%) & \\ \begin{array}{l}\text { Stage } \\ \text { Early (I, II) }(n=30)\end{array} & 26(42.6 \%) & 4(21.1 \%) & 0.090 \\ \text { Advanced (III, IV) }(n=50) & 35(57.4 \%) & 15(78.9 \%) & \\ \text { Risk group } & 11(18.0 \%) & 1(5.3 \%) & 0.009^{*} \\ \text { Low }(n=12) & 37(60.7 \%) & 7(36.8 \%) & \\ \text { Intermediate }(n=44) & 13(21.3 \%) & 11(57.9 \%) & \\ \text { High }(n=24) & & \end{array}$

Data are expressed as number (\%); $p>0.05=$ not significant; $p \leq 0.05=$ significant

CHL classic Hodgkin's lymphoma, NLPHL nodular lymphocyte predominant Hodgkin's lymphoma

et al. showed OS and EFS, $98 \%$ and $86.2 \%$, respectively [21].

Survival rate was significantly affected by few clinical and pathological factors, B symptoms, stage, and risk group. In our study, 5-year survival rate was significantly lower in advanced stage (III and IV) in comparison with early stage (I and II) $p=0.022$. Sherief et al., Dinand et al., and Smith et al. reported similar results, $p=0.006, p=0.0001, p<0.001$, respectively $[17,25,26]$. Presence of B symptoms was borderline significantly 

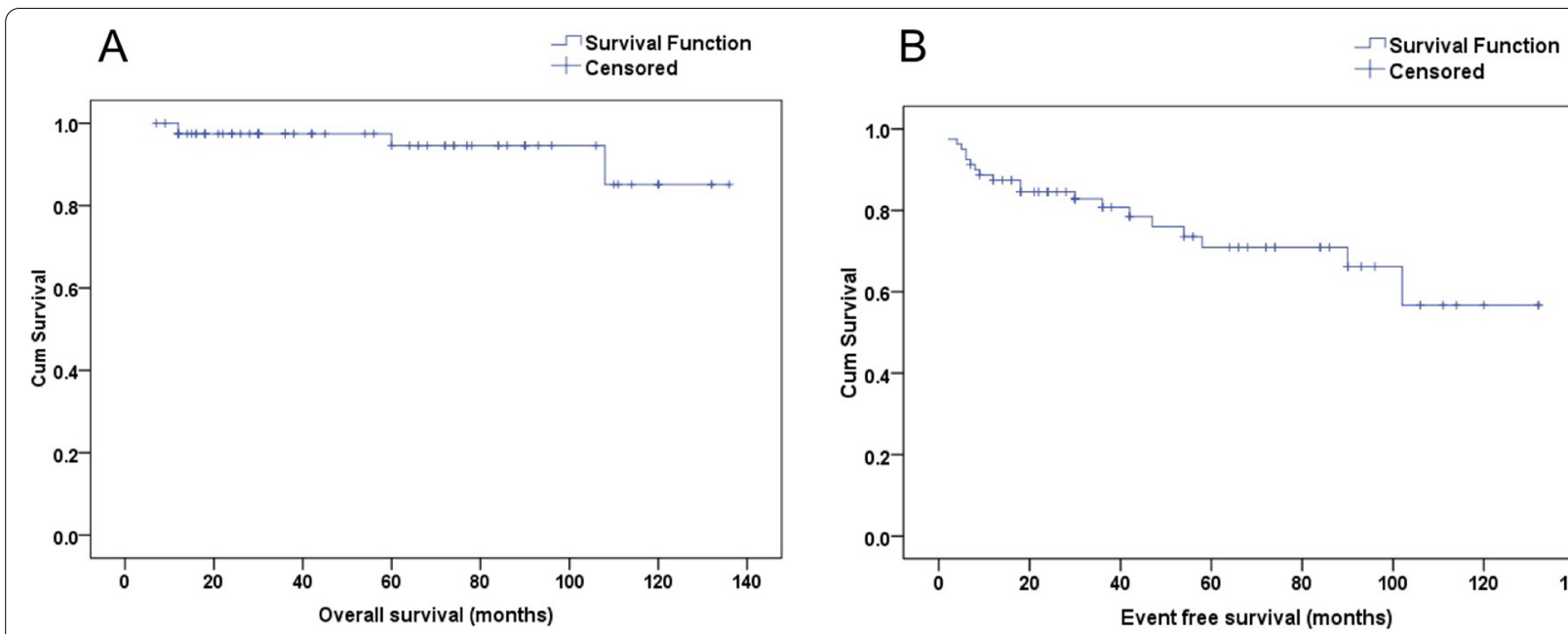

Fig. 1 (A) Five-year overall survival. (B) Five-year event-free survival of Hodgkin's lymphoma pediatric patients
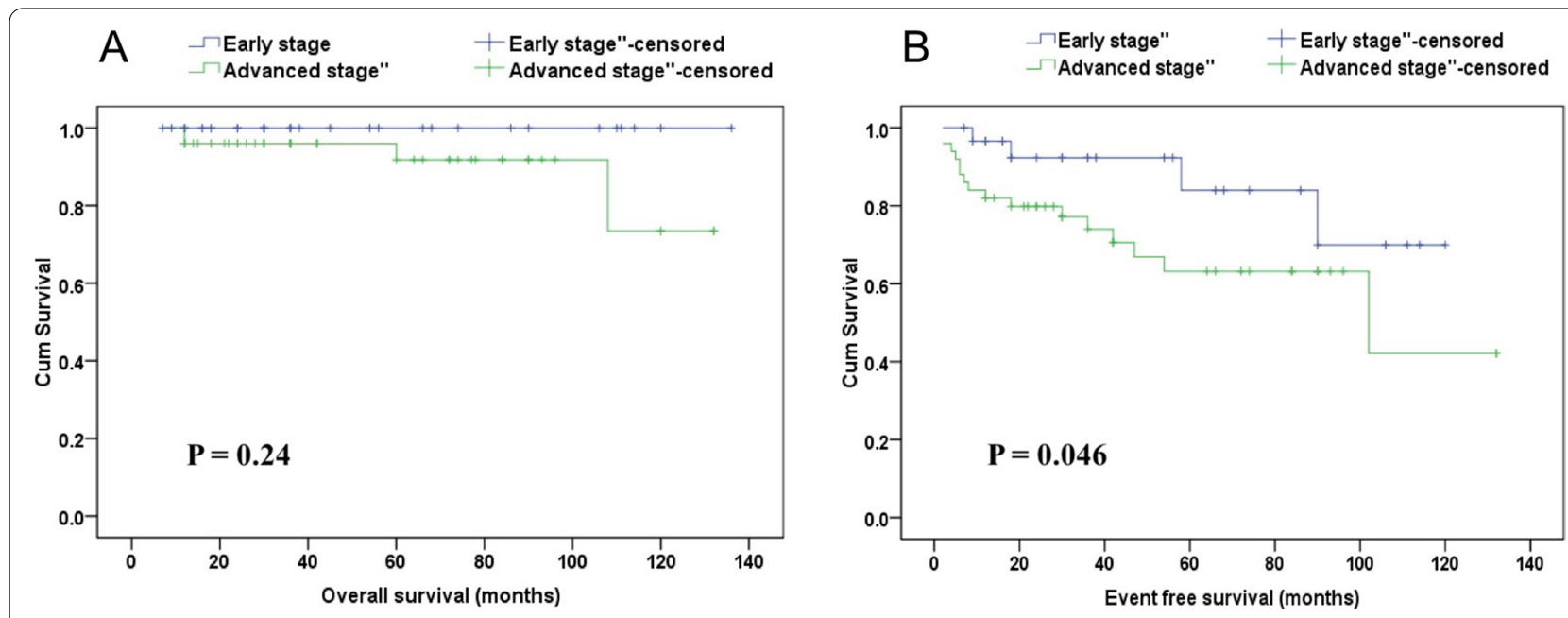

Fig. 2 (A) Stage-related overall survival. (B) Stage-related event-free survival of Hodgkin's lymphoma pediatric patients

associated with lower 5 -year survival rate $(p=0.05)$ while it was significant in other studies, $p=0.005$ [25], $p<0.001$ [27], respectively. We did not find any significant association between histopathological subtypes and 5-year survival rate $(p=0.395)$. But Sherief et al. and Smith et al. found significant correlation between NS subtype and lower survival rate $(p=0.001)$ [17] and $(p=0.02)$ [26], respectively.

A previous study performed on a HL cohort in Saudi Arabia found that the xeroderma pigmentosum complementation group G (XPG) repair gene had statistically significant association with cHL patient survival [27]. The limitation of our study was that we did not correlate our results with genetic studies.
The association of DADA2 (deficiency of adenosine deaminase 2) with lymphoproliferation is well known [28]. In our study, we report familial HL in two children with a novel deleterious mutation in ADA2 and associated with DADA2. The details of both cases were reported before [29].

In our cohort, one patient developed secondary leukemia (AML). This 14-year-old patient was diagnosed with intermediate risk HL (stage IIIA, non-bulky), and was in remission for 54 months. He presented with fever, fatigue, lymphadenopathy, and hepatosplenomegaly. The $\mathrm{BM}$ and immunophenotype was compatible with AML (FAB: M0). A lymph node biopsy showed a myeloid sarcoma. The details were reported before [30]. 

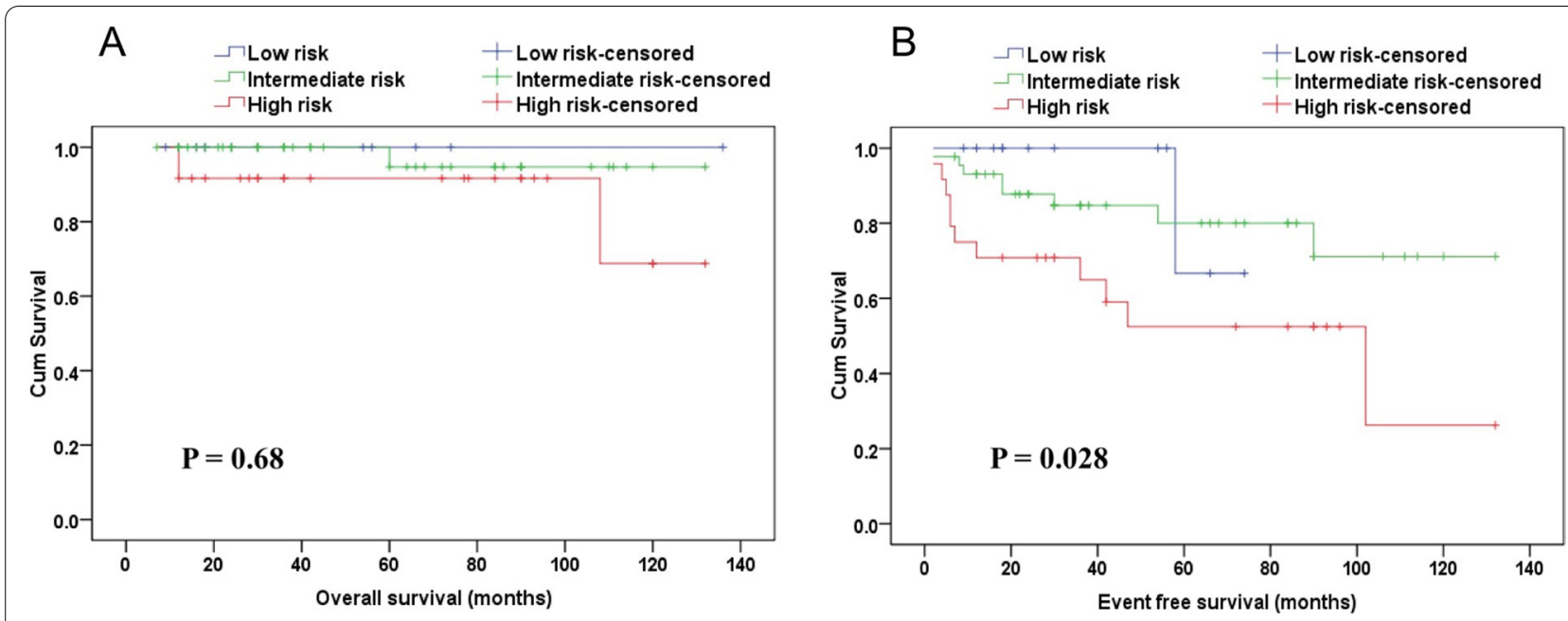

Fig. 3 (A) Risk-related overall survival. (B) Risk-related event-free survival of Hodgkin's lymphoma pediatric patients

\section{Conclusion}

In the last few decades, the outcome of HL especially in pediatric age was improved considerably in the developing countries. Our study provided a unique descriptive study of childhood HL with valuable insight into the long-term outcome and late toxicity in Saudi Arabia. The efficacy of our management strategies illustrated an excellent EFS and OS. So, our results are comparable to other studies in the Middle East and European countries with a little difference in the prominent histopathological subtypes which may be related to the difference in genetic background in the gulf population.

\section{Abbreviations}

HL: Hodgkin's lymphoma; EFS: Event-free-survival; IRB: Institute review board; WHO: World Health Organization; CT: Computed tomography; PET: Positron emission tomography; CBC: Complete blood count; ABVD: Doxorubicin (adriamycin), bleomycin, vinblastine, and dacarbazine; COG: Children's Oncology Group; COPP: Cyclophosphamide, vincristine, procarbazine, prednisone; R-CHOP: Rituximab-cyclophosphamide, hydroxydaunomycin, vincristine, and prednisolone; IFRT: Involved filed radiotherapy; ICE: Ifosfamide/carboplatin/etoposide; ESHAP: Etoposide/solu-medrol/high dose ara-c/platinum "cisplatin"; CR: Complete response; SER: Slow early responders; VGPR: Very good partial response; RER: Rapid early responders; SPSS: Statistical package for social sciences; CR1: Complete remission after first line therapy; CR2: 2Nd complete remission; CHL: Classic Hodgkin's lymphoma; NLPHL: Nodular lymphocyte predominant Hodgkin lymphoma; R/R: Relapsed/refractory; OS: Overall survival; NS: Nodular sclerosis; MC: Mixed cellularity; LR: Lymphocyte rich; LD: Lymphocyte depleted; EBV: Epstein-Barr virus; DADA2: Deficiency of adenosine deaminase 2 .

\section{Acknowledgements}

The authors would like to thank SANAD Children's Cancer Support Association for helping and support the research of children with cancer.

\section{Authors' contributions}

NA analyzed and interpreted the patient data. MA collected the data. GE shared in draft writing. QS collected the data. WI collected the data. $\mathrm{HH}$ shared in draft writing. $A B$ shared in revision of the article. MO shared in draft writing. SA shared in revision of the article. MA shared in revision of the article.
SA collected the data. MA collected the data. OA shared in draft writing. FA shared in draft writing. OA shared in revision of the article. YE interpreted the patient data and she had the main role in critical revision of the article and he was a major contributor in writing the manuscript. All authors read and approved the final manuscript.

\section{Funding}

The authors disclosed receipt of financial support for the research, authorship, and/or publication of this article from SANAD Children's Cancer Support Association and SANAD Research Grants Program (Grant Number: RGP-2017-02).

\section{Availability of data and materials}

The data that support the findings of this study are available from a passwordprotected database in Prince Sultan Military Medical City, Riyadh, Saudi Arabia. But restrictions apply to the availability of these data, which were used under license for the current study, and so are not publicly available. Data are however available from the authors upon reasonable request and with permission of Prince Sultan Military Medical City.

\section{Declarations}

Ethics approval and consent to participate

Institute review board (IRB), of Prince Sultan Military Medical City Riyadh Saudi Arabia, approved this retrospective study with committee's reference number 1390 (HP-01-R079).

\section{Consent for publication}

Not applicable.

\section{Competing interests}

The authors declare that they have no competing interests.

\section{Author details}

${ }^{1}$ Department of Pediatric Hematology/Oncology, Prince Sultan Military Medical City, Riyadh, Riyadh 11159, Saudi Arabia. ${ }^{2}$ Department of Central Military Laboratory and Blood Bank, Prince Sultan Military Medical City, Riyadh, Saudi Arabia. ${ }^{3}$ Department of Pathology and Laboratory Medicine, Ministry of National Guard Health Affairs, King Abdullah International Medical Research Center, King Saud bin Abdulaziz University for Health Sciences, Riyadh, Saudi Arabia. ${ }^{4}$ Pathology Department, King Khalid University Hospital, King Saud University, Riyadh, Kingdom of Saudi Arabia. ${ }^{5}$ Department of Pediatric Oncology, National Cancer Institute, Cairo University, Cairo, Egypt.

Received: 14 October 2020 Accepted: 18 July 2021

Published online: 16 August 2021 


\section{References}

1. Thomas RK, Re D, Zander T, Wolf J, DiehI V. Epidemiology and etiology of Hodgkin's lymphoma. Ann Oncol. 2002;13(4):147-52. https://doi.org/10. 1093/annonc/mdf652.

2. Elborai Y, Elgammal A, Salama A, Fawzy M, El-Desouky ED, Attia I, et al. Cyclooxygenase-2 expression as a prognostic factor in pediatric classical Hodgkin lymphoma. Clin Transl Oncol. 2020;22:1539-47. https://doi.org/ 10.1007/s12094-020-02297-8.

3. Chang ET, Zheng T, Weir EG, Borowitz M, Mann RB, Spiegelman D, et al. Childhood social environment and Hodgkin's lymphoma: new findings from a population-based case-control study. Cancer Epidemiol Biomarkers Prev. 2004;13(8):1361-70.

4. Glaser SL, Clarke CA, Nugent RA, Stearns CB, Dorfman RF. Social class and risk of Hodgkin's disease in young-adult women in 1988-94. Int J Cancer. 2002;98(1):110-7. https://doi.org/10.1002/ijc.10164.

5. Dinand V, Arya LS. Epidemiology of childhood Hodgkin's disease: is it different in developing countries? Indian Pediatr. 2006;43(2):141-7.

6. Jemal A, Siegel R, Ward E, Hao Y, Xu J, Thun MJ. Cancer statistics. CA Cancer J Clin. 2009;59(4):225-49. https://doi.org/10.3322/caac.20006.

7. Alhashmi H, Kandil M, Alhejazi A, Motabi I, Sagheir A, Alzahrani M, et al. Hodgkin's lymphoma: Saudi Lymphoma Group's clinical practice guidelines for diagnosis, management and follow-up. Saudi J Med Med Sci. 2019;7(3):195-201. https://doi.org/10.4103/sjmms.sjmms_96_19.

8. Belgaumi AF, Pathan GQ, Siddiqui K, Ali AA, Al-Fawaz I, Al-Sweedan S, Ayas M, Al-Kofide AA. Incidence, clinical distribution, and patient characteristics of childhood cancer in Saudi Arabia: a population-based analysis. Pediatr Blood Cancer. 2019;66(6): e27684. https://doi.org/10.1002/pbc. 27684.

9. Fitzmaurice C, Allen C, Barber RM, Barregard L, Bhutta ZA, Brenner H, et al. Global, regional, and national cancer incidence, mortality, years of life lost, years lived with disability, and disability-adjusted life-years for 32 cancer groups, 1990 to 2015: a systematic analysis for the Global Burden of Disease Study. JAMA Oncol. 2017;3(4):524-48. https://doi.org/10.1001/ jamaoncol.2016.5688.

10. Maggioncalda A, Malik N, Shenoy P, Smith M, Sinha R, Flowers CR. Clinical, molecular, and environmental risk factors for Hodgkin lymphoma. Adv Hematol. 2011:736261. doi: https://doi.org/10.1155/2011/736261.

11. Oguz A, Karadeniz C, Okur FV, Citak EC, Pinarli FG, Bora H, et al. Prognostic factors and treatment outcome in childhood Hodgkin disease. Pediatr Blood Cancer. 2005;45(5):670-5. https://doi.org/10.1002/pbc.20487.

12. Campo E, Swerdlow SH, Harris NL, Pileri S, Stein H, Jaffe ES. The 2008 WHO classification of lymphoid neoplasms and beyond: evolving concepts and practical applications. Blood. 2011;117(19):5019-32. https://doi.org/10. 1182/blood-2011-01-293050.

13. Lister TA, Crowther D, Sutcliffe SB, Glatstein E, Canellos GP, Rosenberg $\mathrm{RC}$, et al. Report of a committee convened to discuss the evaluation and staging of patients with Hodgkin's disease: cotswolds meeting. J Clin Oncol. 1989;7(11):1630-6. https://doi.org/10.1200/JCO.1989.7.11.1630.

14. Hasenclever D, DiehI V. A prognostic score for advanced Hodgkin's disease: international prognostic factors project on advanced Hodgkin's disease. N Engl J Med. 1998;339(21):1506-14. https://doi.org/10.1056/ NEJM199811193392104.

15. Cheson BD, Horning SJ, Coiffier B, Shipp MA, Fisher RI, Lister JM, et al. Report of an international workshop to standardize response criteria for non-Hodgkin's lymphomas NCI Sponsored International Working Group. J Clin Oncol. 1999;17(4):1244. https://doi.org/10.1200/JCO.1999.17.4.1244.

16. Aquino S, Clavio M, Rossi E, Vignolo L, Miglino M, Spriano M, et al. Therapy of Hodgkin's lymphoma in clinical practice: a retrospective long-term follow-up analysis. Oncol Lett. 2011;2:289-95. https://doi.org/10.3892/ol. 2011.255.

17. Sherief LM, Elsafy UR, Abdelkhalek ER, Naglaa MK, Rabab E, Tamer HH, et al. Hodgkin lymphoma in childhood, clinicopathological features and therapy outcome at 2 centers from a developing country. Medicine. 2015;94(15):670-6. https://doi.org/10.1097/MD.0000000000000670.

18. Stefan DC, Stones D. How much does it cost to treat children with Hodgkin lymphoma in Africa? Leuk Lymphoma. 2009;50(2):196-9. https://doi. org/10.1080/10428190802663205.

19. Baez F, Ocampo E, Conter V, Flores A, Gutierrez T, Malta A, et al. Treatment of childhood Hodgkin's disease with COPP or COPP-ABV (hybrid) without radiotherapy in Nicaragua. Ann Oncol. 1997;8(3):247-50. https://doi.org/ 10.1023/a:1008200210674.

20. Feldman AL, Pittaluga S, Jaffe ES. Classification and histopathology of the lymphomas. In: Canellos GP, Lister TA, Young B, editors. The Lymphomas. 2nd ed. Philadelphia USA: Saunders Elsevier; 2006. p. 2-25.

21. Pourtsidis A, Doganis D, Baka M, Bouhoutsou D, Varvoutsi M, Synodinou $M$, et al. Differences between younger and older patients with childhood Hodgkin lymphoma. Pediatr Hematol Oncol. 2013;30(6):532-6. https:// doi.org/10.3109/08880018.2013.823471.

22. Arya LS, Dinand V, Thavaraj V, Bakhshi S, Dawar R, Rath GK, et al. Hodgkin's disease in Indian children: outcome with chemotherapy alone. Pediatr Blood Cancer. 2006;46(1):26-34. https://doi.org/10.1002/pbc.20157.

23. Audouin J, Diebold J, Nathwani B, Ishak E, MacLennan K, Mueller-Hermel-

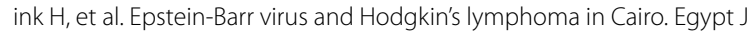
Hematop. 2010;3(1):11-8. https://doi.org/10.1007/s12308-010-0059-3.

24. Kamer Mutafoğlu Uysal, Riza Çetingöz, Dilek Güneş, Ayşe Demiral, Erdener Özer, Handan Çakmakçi, et al. Clinical characteristics and therapy outcome of pediatric Hodgkin's lymphoma - a single centre experience from the west part of Turkey. Turkish J Cancer 2007;37(3):98-108.

25. Dinand V, Dawar R, Arya LS, Unni R, Mohanty B, Singh R, et al. Hodgkin's lymphoma in Indian children: prevalence and significance of EpsteinBarr virus detection in Hodgkin's and Reed-Sternberg cells. Eur J Cancer. 2007:43(1):161-8. https://doi.org/10.1016/j.ejca.2006.08.036.

26. Smith RS, Chen $Q$, Hudson MM, Link MP, Kun L, Billett HW, et al. Prognostic factors for children with Hodgkin's disease treated with combinedmodality therapy. J Clin Oncol. 2003;21(10):2026-33. https://doi.org/10. 1200/JCO.2003.07.124.

27. Al Sayed Ahmed H, Raslan WF, Deifalla AHS, Fathallah MD. Overall survival of classical Hodgkins lymphoma in Saudi patients is affected by XPG repair gene polymorphism. Biomed Rep. 2019;10(1):10-16. doi:https:// doi.org/10.3892/br.2018.1165.

28. Alsultan A, Basher E, Alqanatish J, Mohammed R, Alfadhel M. Deficiency of ADA2 mimicking autoimmune lymphoproliferative syndrome in the absence of livedo reticularis and vasculitis. Pediatr Blood Cancer. 2018;65(4). doi: https://doi.org/10.1002/pbc.26912.

29. Alabbas F, Elyamany G, Alsharif O, Hershfield M, Meyts I. Childhood Hodgkin lymphoma: think DADA2. J Clin Immunol. 2019;39(1):26-9. https://doi. org/10.1007/s10875-019-0590-7.

30. Alkhayat N, Elyamany G, Elborai Y, Sedick Q, Al-Shahrani M, Al-Sharif $\mathrm{O}$, et al. Rare cytogenetic abnormalities and their clinical relevance in pediatric acute leukemia of Saudi Arabian population. Mol Cytogenet. 2019;12:42-52. https://doi.org/10.1186/s13039-019-0454-0.

\section{Publisher's Note}

Springer Nature remains neutral with regard to jurisdictional claims in published maps and institutional affiliations. 